\title{
Economic Operation of Island Microgrid Based on Optimal Scheduling of Energy Storage
}

\author{
Xiaoyan Zhang ${ }^{1,2, a, *}$, Zhenggang $\mathrm{Yu}^{3, \mathrm{~b}}$, Xiangyun $\mathrm{Fu}^{3, \mathrm{c}}$, and $\mathrm{Zhe} \mathrm{Li}^{1,2, \mathrm{~d}}$ \\ ${ }^{1}$ NARI Group Corporation / State Grid Electric Power Research Institute, No.19, Chengxin Avenue, \\ Jiangning District, Nanjing City, Jiangsu Province, China \\ ${ }^{2}$ NARI Technology Development Co., Ltd., No.19, Chengxin Avenue, Jiangning District, Nanjing City, \\ Jiangsu Province, China \\ ${ }^{3}$ State Grid Lianyungang Power Supply Company, No.1,Xingfu Road, Haizhou District, Lianyungang City, \\ Jiangsu Province, China \\ a zhangxiaoyan@sgepri.sgcc.com.cn, b yuzg@js.sgcc.com.cn, \\ ${ }^{\mathrm{c}}$ fuxy@js.sgcc.com.cn, ${ }^{\mathrm{d}}$ lizhe6@sgepri.sgcc.com.cn
}

Keywords: energy storage; State of Charge; island microgrid; economic operation

\begin{abstract}
An economic operation control strategy of island microgrid based on optimal scheduling of energy storage is proposed in this paper. The state of charge (SOC) and type of microgrid is fully considered in this strategy. In grid-tied island microgrid, the energy storage charging control is carried out according to the SOC condition at valley electricity price, and the energy storage discharging control is carried out according to the SOC condition at peak electricity price. In standalone island microgrid, the energy storage control of charging and discharging is carried out according to the renewable energy power generation and SOC value. The strategy proposed can effectively extend the battery life and improve the operation economy of microgrid making full use of price difference between peak and valley electricity price.
\end{abstract}

\section{Introduction}

In recent years, microgrid as a new power supply mode has obtained fast development and has broad application prospects, especially in remote mountainous areas, remote villages, islands and the end of urban distribution network where the power grid is power grid not easy to reach. There are numerous islands in our country, including 6536 islands of more than 500 square meters. Total area of all islands is more than 72800 square kilometres, and island coastline is 14217.8 kilometres long. As the island is far away from the mainland, the power supply modes of islands are divided into two types [1].One mode is that the island power grid is connected to mainland power grid through the submarine cable or power supply overhead line. In which, it needs huge investment for laying submarine cable or overhead lines, and the power supply reliability in many islands is low because the $10 \mathrm{kV}$ power supply lines into the island are single circuit lines, in which it is difficult to ensure the stability of the island power supply because it needs a long time to restore power supply once the submarine cable or other power supply facilities are in failure, and the voltage qualified rate is low because of the large power supply radius. The other mode is that the island is powered by the diesel generator and is not connected to mainland power, in which the island's ecological environment is seriously affected because of high carbon emissions of diesel power generation with high costs and low power generation efficiency. The development of microgrid technology provides a new solution for island power supply. And more and more islands use microgrid power supply mode providing electricity for the island development and desalination using renewable energy power generation and energy storage [2].

The ability of microgrid system to withstand perturbation is relatively weak because of large proportion of intermittent renewable energy power generation. In order to make full use of advantages and benefits of renewable energy power generation, a certain capacity of energy storage 
must be configured to balance its random fluctuations, maintain system stability, improve power quality, provide uninterrupted power supply function [3]. The configuration of energy storage system and the charging and discharging control strategy is directly related to the operation economy of microgrid due to the high cost of energy storage system. At present, the most widely used energy storage system is the battery, whose effective cumulative life is related to the state of charge (SOC). The life of the battery is usually defined by the cycle life of the battery. When the battery discharge depth is $100 \%$, the actual life of the battery is about 200-250 times charge and discharge cycle; when the battery discharge depth is reduced to $50 \%$, it allows the charge and discharge cycle can be increased to 500-600 times; When the discharge depth is reduced to 30\%, the allowable charge and discharge cycles can be as high as about 1200 times. Therefore, in order to extend the battery life, its optimal scheduling strategy needs to pay attention to the battery SOC, to prevent the battery in the state of deep discharge.

\section{Characteristics of island microgrid}

Although it is lack of power resources in the island, but it is rich in ocean energy, solar energy, wind energy and other renewable energy [4]. So it is of great significance to construct microgrid project to solve the problem of island residents' electricity making full use of island clean energy.

\subsection{Characteristics of clean energy distribution}

(1) Ocean energy

Ocean resources in our country are rich, and the coastline contains a wealth of energy. Ocean energy mainly includes wave energy, tidal energy, temperature difference and so on [5]. Tidal energy is a periodic water natural fluctuation phenomenon, which is caused by the moon and the sun and other celestial bodies, and is also the earliest human understanding and use of ocean energy. Tidal power generation is the earliest use of ocean energy, and the technology is most mature, which is using the energy of the water to make water wheel generator to produce electricity like hydroelectric power generation. Wave power generation is the fastest growing ocean energy utilization after tidal power generation. China is in the Pacific west bank, and it has a typical monsoon climate. So wave energy distribution in our country shows a more obvious seasonal variation. Wave energy is the most abundant during winter for the whole year under the influence of the monsoon, especially in Taiwan straits, the northeastern South China Sea and other regions. The existing statistics show that the average theoretical power of the near-shore wave energy in China is more than 10 million $\mathrm{kW}$, and the most abundant areas are located in the coastal area of Taiwan Province. The average theoretical power is 4.29 million $\mathrm{kW}$, which is about $33 \%$ of the total. And the wave of energy resources are also more abundant in Shandong, Zhejiang, Fujian and Guangdong provinces, , the average theoretical power between 1.61-2.05 million kW, a total of 7.06 million $\mathrm{kW}$, accounting for $55 \%$ of the total.

(2) Solar energy

In addition to the rich ocean energy, the island also contains a wealth of solar energy resources. Taking Zhejiang Province as an example, the average annual sunshine hours of Zhejiang Province is $1800 \sim 2300 \mathrm{~h}$ and the total annual solar radiation is $4000-4600 \mathrm{MJ} / \mathrm{m}^{2}$. The total annual solar energy of Zhejiang Province is above $1100 \mathrm{kWh} / \mathrm{m}^{2}$ which is converted into electric energy. Solar seasonal distribution is uneven, which is largest in summer and smallest in winter. Solar daily distribution is large before and after noon and small in morning and night. Solar geographic distribution is large in the north island and small in the south island.

(3) Wind energy

Wind energy resource is very rich although the electricity is scarce in the island. Take Zhejiang Province for example, in which there is rich wind energy resource from south to north and it is one of the regions where there is the most abundant wind energy. In addition to the relatively large area of Zhoushan and Dongtou islands, the average annual wind speed of many islands can be up to $6 \mathrm{~m} / \mathrm{s}$ or more, the effective wind speed can be more than 7000h, the effective wind energy density can be up to $350 \mathrm{~W} / \mathrm{m}^{2}$ or more. Take the average wind speed $5 \mathrm{~m} / \mathrm{s}$, the annual effective wind energy 
density $200 \mathrm{~W} / \mathrm{m}^{2}$ for example, the total storage capacity of wind energy on island land surface in Zhejiang province can be up to $39000 \times 10^{4} \mathrm{~kW}$. It can be seen that there is a high utilization value in the wind energy in the island. However, the use of wind energy also has a problem of instability and discontinuity. The distribution of wind energy in different quarters is not uniform, which is abundant from midautumn to early spring and weak in summer.

The analysis of the distribution characteristics of wave energy, solar energy and wind energy in the island shows that the clean energy has complementarity in time distribution. In winter and spring, the solar energy is smaller and the wind energy and wave energy are larger. In summer, the wind energy and wave energy are smaller and the solar energy is larger. In daytime, the solar energy is larger, the wind energy and wave energy are larger. Therefore, we can make full use of the complementary characteristics of clean energy in the island and use microgrid to achieve island power supply.

\subsection{Load characteristics}

\section{(1) Residential electricity load}

The island economy usually is dominated by fisheries or tourism, a few island agricultural or island industries. In the islands dominated by tourism, there is a large gap in electricity in the tourist season. So, it needs to take power brownouts measures to ensure the power supply for important load. The lack of electricity supply will affect the quality of tourism services and the quality of life of the residents in the island.

(2) Time-shifted load

Groundwater resources are limited in most islands, and seawater intrusion is heavy. And even the islanders could only eat brackish water with high chlorinated ions in the past. Seawater desalination is an important addition to fresh water supply, an important complement to water resources and strategic reserves. It is feasible in economic and environment to use seawater desalination to solve the problem of water shortage in coastal areas and islands, which is also the best choice in many cases. However, seawater desalination is high energy-consuming industries. So developing cheap renewable energy power generation for desalination will be an important way to solve the high cost of desalination.

Seawater desalination belongs to time-shifted load, and can be converted into time-shifted electrical load. When the power output of wind / PV power generation is greater than the load demand and the battery charge reaches the limit, desalination load can be used to better track the wind / PV power output, which can reduce the phenomenon of wind abandoning and solar abandoning, and improve the utilization efficiency of clean energy power generation.

\subsection{Microgrid characteristics}

As an independently controllable power supply system consisting of distributed power, energy storage and load, microgrid is the most effective form of realizing distributed power efficiency. Microgrid power supply mode realizes higher overall investment efficiency and energy conversion efficiency with less environmental costs. Island microgrid system can be independent of grid on the mainland, but also can be connected to the grid through the submarine cable, which has high flexibility. Microgrid provides users with clean and reliable power supply through mutual coordination and complement of distributed power.

(1) Grid-tied island microgrid

Power grid in large islands is usually connected to grid on the mainland through the submarine cable, due to higher requirements for total demand and reliability of electricity. Power shortage problems still exist because of restriction of the island conditions. Therefore, it needs to make full use of clean energy in the island to establish a grid-tied island microgrid to satisfy load power supply requirements. In order to ensure the safe and stable operation of the microgrid, it needs to configure a certain capacity of energy storage. The charging and discharging control strategy of energy storage is directly related to the life of energy storage and the operation economy of microgrid, which is the key research content of this paper. Structure chart of grid-tied island microgrid is shown in Fig.1. 


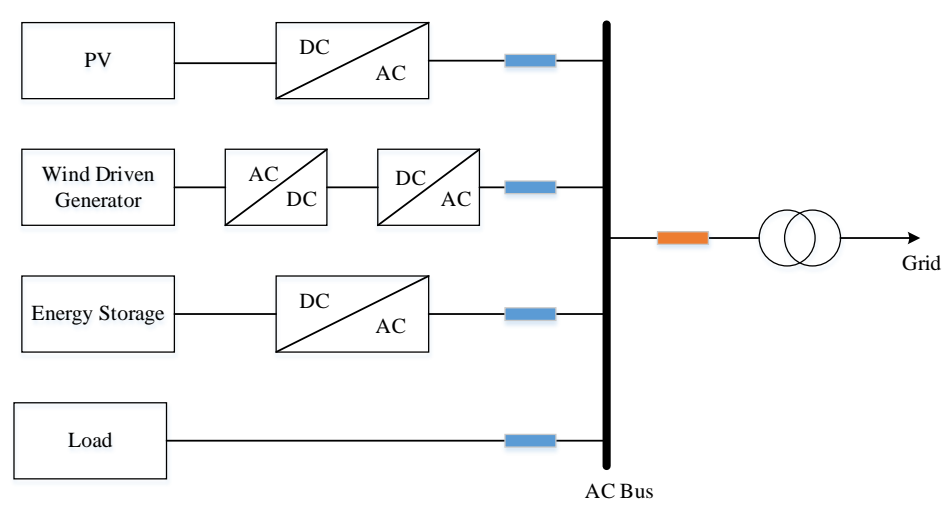

Fig.1. Structure chart of grid-tied island microgrid

(2) Stand-alone island microgrid

For other remote islands, the maximum load is limited, the transport distance is far, the island area is narrow, laying submarine cable in the technical and economic aspects need to pay a greater price, so it needs to make full use of clean energy power generation. The wind-solar-dieselmicrogrid system is a typical independent microgrid system. Diesel generators as a system of standby power, has the following two roles. (1) Emergency power supply. When the renewable energy and the battery cannot meet the load demand, or the battery charge state (SOC) reaches the minimum limit, the diesel generator starts to provide emergency power, so as to ensure the reliability of the microgrid system power supply. (2) Supplement power supply. Due to the randomness and volatility of renewable energy power generation, it is difficult to ensure the charging power and charging time of the battery only by renewable energy. The diesel generator as a supplementary power supply for the battery can provide stable charging power and guaranteed charging time to effectively protect the battery and to extend the battery life. If the battery loss is too fast, it will greatly weaken the stability and economy of the microgrid system and economy, especially for the island in which the traffic is inconvenient, and transportation costs are high. It will bring huge potential economic losses if the battery often needs replacement and maintenance. Structure chart of stand-alone island microgrid is shown in Fig.2.

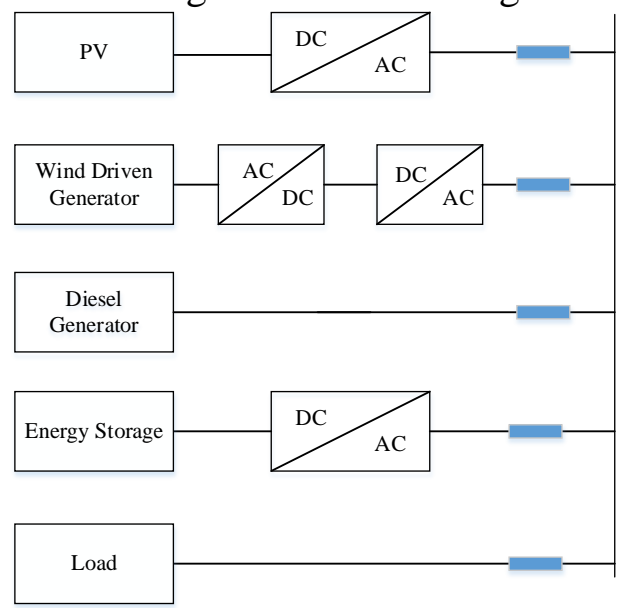

Fig.2. Structure chart of stand-alone island microgrid

\section{Energy storage configuration principles}

It has a great influence on microgrid economic operation whether the capacity configuration of energy storage system is reasonable. If the capacity is too small, the excess electricity of system cannot be fully storaged, which will cause the micro-grid power generation waste. If the capacity is too large, it increases the investment and affects the energy storage service life because of long-term lack of charge for energy storage. Therefore, it is very important to select appropriate capacity of energy storage, which generally needs to meet the two requirements. First, the capacity of energy 
storage should be able to meet the needs of the system. Second, the choice of capacity should meet a certain degree of economy.

\subsection{Energy storage configuration principles in distributed generation}

Energy storage in the distributed generation takes stabilizing the power consumption of distributed power as the basic goal, the greater the degree of repression, and the smoother the output curve of distributed generation. However, under different applications, storage configuration principle is different. Therefore, the storage configuration objectives and evaluation criteria should be defined first. At present, the main storage configuration objectives include the technical requirements satisfaction of grid access, power output fluctuations, and stable output according to smooth / predictive target curve, etc. The evaluation criteria commonly used include fluctuation reduction rate, standard deviation, symmetrical distribution characteristics of energy storage power, investment cost minimum and so on.

In addition, the energy storage configuration in the distributed generation is also affected by many factors, which can be divided into internal and external factors. Internal factors refer to the own characteristic of energy storage, such as efficiency, allowable charge and discharge depth, etc. External factors include characteristics of distributed power generation, the typical power generation data and the access mode of energy storage.

\subsection{Energy storage configuration principles in microgrid}

Compared with the distributed generation, the power generation of the microgrid is generally in accordance with the principle of local consumption, based on the load. The ratio of the wind-solarwater power should make full use of the complementary of the local wind, solar and water resources to make the overall output of the wind-solar-water power as smooth as possible and fluctuation as minimal as possible. Under the premise in considering the economy, energy storage should ensure that important load have continuous power supply for some time in extreme conditions in microgrid system. As capacity of the distributed generation in the microgrid is small, the fluctuation of distributed generation has little effect on the main grid, so the configuration of the energy storage system depends mainly on the load demand.

According to the four microgrid application mode, energy storage system can be configured in the grid-tied and stand-alone microgrid. When the microgrid is running connected to the grid, the energy storage system works in accordance with the way of discharging in daytime and charging at night based on the spread of peak and valley electricity price. When the microgrid is running off the grid, the energy storage system works in accordance with the way of charging in daytime and discharging at night.

\section{Microgrid Economic Operation Strategy}

Energy storage is an important part of microgrid, but also the shortest life-cycle in microgrid system equipment, whose usage is directly related to the economy and stability of the microgrid system. In this paper, the charging and discharging process of battery is discretized, and the energy storage optimization scheduling strategy that is aimed at island microgrid economic operation and is suitable for the engineering application is proposed, in which next 24 hours energy storage scheduling objectives is determined to achieve microgrid economic operation.

(1) Grid-tied island microgrid

As to islands with support of large grid, a grid-tied island microgrid can be built, such as gridtied microgrid in Luxi Island. It contains two microgrids and has many working modes, in which each microgrid can run off the grid independently, and also can run connected to the grid independently, and the two microgrids can also run as microgrid unions.

With the support of large grid, energy storage system can be in accordance with the peak and valley electricity price to control charging and discharging in considering the operation of microgrid economy. The energy storage charging control is carried out according to the SOC condition at valley electricity price, and the energy storage discharging control is carried out according to the 
SOC condition at peak electricity price. Flow chart of energy storage optimization scheduling policy is shown in Fig.3. In Fig.3, $\mathrm{N}$ is energy storage group number. SOC is state of charge. $\mathrm{T}$ is the current time. $\mathrm{SOC}_{\mathrm{H}}$ is upper limit of SOC. $\mathrm{SOC}_{\mathrm{L}}$ is lower limit of SOC. $\mathrm{P}_{\text {cha }}$ is the charge power for energy storage, unit: $\mathrm{kW}$. $\mathrm{P}_{\text {dis }}$ is discharge power for energy storage, unit: $\mathrm{kW}$. $\mathrm{S}$ is the capacity of energy storage system, unit: $\mathrm{kWh}$.

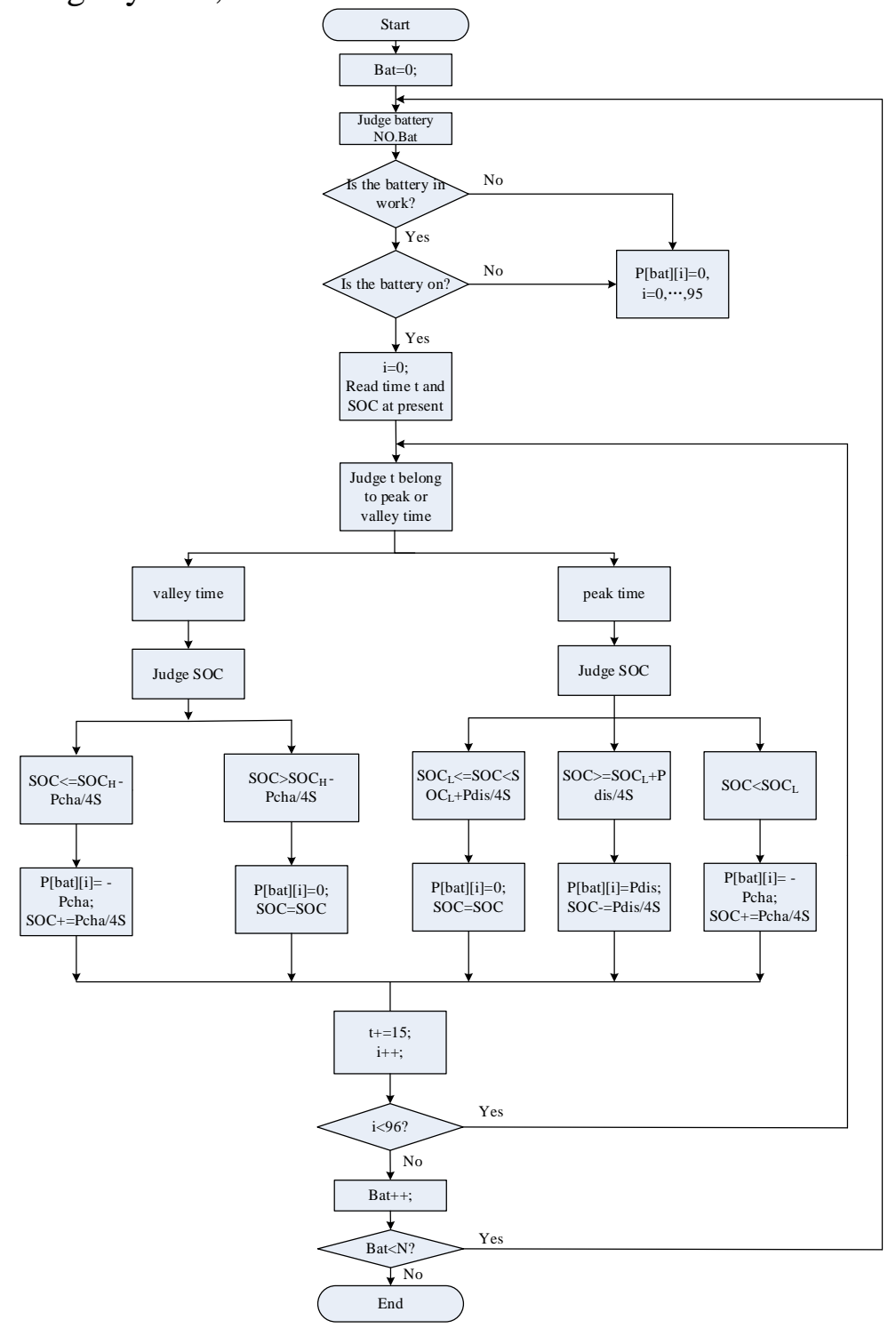

Fig.3. Flow chart of energy storage optimization scheduling strategy about grid-tied island microgrid.

The energy storage optimization scheduling strategy of grid-tied microgrid based on the peak and valley electricity price policy and SOC is proposed in this section, in which next 24 hours energy storage scheduling objectives is given which contains a total of 96 data with one data every 15 minutes. The energy storage optimization scheduling strategy has been used in microgrid EMS (energy management system) in Luxi Island. The working rusults show that the strategy can improve the operation economy of microgrid and has great practical value.

(2) Stand-alone island microgrid

As to the islands with no grids, the stand-alone island microgrid is built in need, such as standalone microgrid in Nanlu Island. Stand-alone island microgrid takes diesel generators as a standby power. When the renewable energy power generation is sufficient, the battery is charged by the renewable energy power if $\mathrm{SOC}<\mathrm{SOC}_{\mathrm{H}}$, otherwise the battery is not charged or discharged. When the renewable energy power generation is insufficient, the load is powered by the battery if SOC $>\mathrm{SOC}_{\mathrm{L}}$, otherwise the load is powered by the diesel generator and the battery is charged by the diesel generator if $\mathrm{SOC} \leq \mathrm{SOC}_{\mathrm{L}}$. 


\section{Conclusion}

As to the economic operation of island microgrid, the characteristics of island microgrid and the principle of energy storage optimal configuration is analysed in this paper, and an economic operation strategy of island microgrid based on optimal scheduling of energy storage is proposed. In grid-tied island microgrid, the energy storage is charged according to the SOC condition at valley electricity price and is discharged according to the SOC condition at peak electricity price so as to obtain the optimal scheduling strategy of energy storage. In stand-alone island microgrid, the charging and discharging control strategy of energy storage is proposed based on the peak and valley electricity price policy and SOC. The economic operation strategy of island microgrid based on optimal scheduling of energy storage proposed in this paper can effectively extend the battery life and improve the operation economy of microgrid with full consideration to SOC.

\section{Acknowledgments}

This work is financially supported by the science and technology program "Research and Development of Key Technology of Island Microgrid Based on Wave Energy and Other Renewable Energy”.

\section{References}

[1] CHEN Jian, Wang Chengshan, and ZHAO Bo. (2012) Economic Operation Optimization of a Stand-alone Microgrid System Considering Characteristics of Energy Storage System. Automation of Electric Power Systems, 36, 25-31.

[2] ZHOU Leiwen, GUI Fukun, and ZHU Aiyi. (2016) Island based Small-size Solar Desalination Device and the Factors on its Water Yield. ENERGY CONSERVATION TECHNOLOGY, 34, 270-274.

[3] Yang Huan, Zhao Rongxiang, and Xin Huanhai. (2013) Development and Research Status of Island Power Systems. TRANSACTIONS OF CHINA ELECTROTECHNICAL SOCIETY, 28, 95105.

[4] Zhong Zhigang, Deng Huiping, Zhou Zhanping, Feng Baoyue, and Jiang Bing. (2017) Operation Optimization of Island Micro-grid Based on Improved PSO Optimization Algorithm. MICROPROCESSORS, 1, 48-52.

[5] ZHANG Xianyong, SHU Jie, and WU Changhong. (2014) Island microgrid based on distributed photovoltaic generation. Power System Protection and Control, 42, 55-61. 